\title{
Article \\ The Subjective Well-Being of Children in Residential Care: Has It Changed in Recent Years?
}

\author{
Carme Montserrat $^{1}{ }^{\circledR}$, Joan Llosada-Gistau ${ }^{1, *}$, Marta Garcia-Molsosa ${ }^{1, *(\mathbb{C})}$ and Ferran Casas ${ }^{2} \mathbb{C}$ \\ 1 Liberi, Research Team on Childhood, Youth and Comunity, Universitat de Girona, 17004 Girona, Spain; \\ carme.montserrat@udg.edu \\ 2 Faculty of Education and Social Sciences, Universidad Andrés Bello, Santiago 7550196, Chile; \\ ferran.casas@udg.edu \\ * Correspondence: jllosada@gencat.cat (J.L.-G.); marta.garcia.molsosa@cmail.cat (M.G.-M.)
}

Citation: Montserrat, Carme, Joan Llosada-Gistau, Marta Garcia-Molsosa, and Ferran Casas. 2022. The Subjective Well-Being of Children in Residential Care: Has It Changed in Recent Years? Social Sciences 11: 25. https://doi.org/ 10.3390/socsci11010025

Academic Editor: Nigel Parton

Received: 29 November 2021

Accepted: 11 January 2022

Published: 14 January 2022

Publisher's Note: MDPI stays neutral with regard to jurisdictional claims in published maps and institutional affiliations.

Copyright: (C) 2022 by the authors. Licensee MDPI, Basel, Switzerland. This article is an open access article distributed under the terms and conditions of the Creative Commons Attribution (CC BY) license (https:// creativecommons.org/licenses/by/ $4.0 /)$.

\begin{abstract}
The subjective well-being of children in residential care is a relevant issue given the practical implications for improving the lives of these children who live in contexts of vulnerability. The question addressed in this respect was: "How does this well-being change over the years"? Thus, the aim of this study was to compare the subjective well-being displayed by adolescents aged 11-14 in residential care in Catalonia (north-eastern Spain) in 2014 to that displayed by adolescents in residential care in 2020. To this end, 572 responses to a questionnaire adapted from the Children's Worlds project (364 from 2014 and 208 from 2020) were analysed with respect to the life satisfaction items. In both 2014 and 2020, the questionnaires had the same wording, and data were disaggregated by gender. No significant differences in means were observed between most of the life satisfaction items in 2014 and 2020, with the exception of satisfaction with friends and classmates and the area where you live, with lower means for these items in 2020. There is a discussion of the possible influence of COVID-19 on these results, while the overall stability of these children's subjective well-being over the years is highlighted.
\end{abstract}

Keywords: subjective well-being; residential care; child protection system; temporal comparability; COVID-19 lockdown

\section{Introduction}

Studies on subjective well-being have increased in recent decades, and, albeit to a lesser extent, this rise has also included research on the well-being of vulnerable populations such as children in the care system. The authors understand subjective well-being to be a psychosocial component of quality of life (Casas 2011). The study of well-being focuses on the evaluations that individuals - in these cases, children-make regarding their own lives, both with regard to individual domains and overall. In this article, we focus on the subjective well-being of children in residential care, comparing the data collection that was performed in 2014 with that of 2020. The article has three main axes: children in residential care; their subjective well-being; and variations in well-being over time, particularly during the COVID-19 pandemic.

\subsection{Residential Care in Spain}

According to data from the Spanish Childhood Observatory (2020), 55\% of children in the Spanish care system are in residential care and $45 \%$ in foster care, while among the latter, $65 \%$ are in kinship family foster care and 35\% are with non-kinship families. The same source indicates that residential care has increased in recent years. One of the reasons for this has been the influx of a large number of children, mainly boys, from the Maghreb and sub-Saharan Africa, who arrive alone and are admitted to residential care. Figure 1 which shows data for Catalonia, where the present research is focused, shows how both 
forms of foster care and pre-adoption care have remained fairly stable over recent years, while residential care has substantially increased.

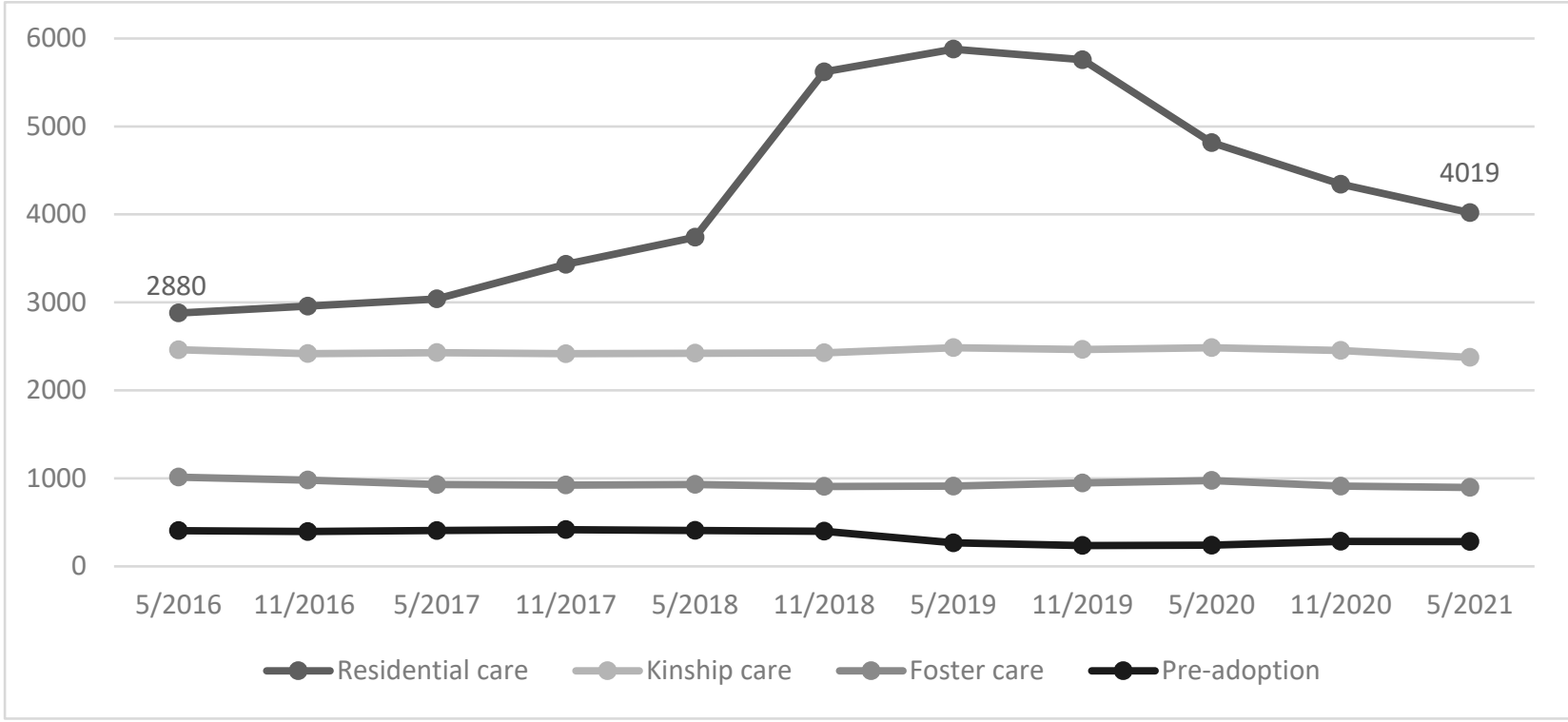

Figure 1. Evolution of care measures in Catalonia (2016-2021). Source: authors' own work, based on official data from the DGAIA (Catalan Directorate General of Child and Adolescent Care), available at https: / / treballiaferssocials.gencat.cat/ (accessed on 1 November 2021).

Thus, when it comes to residential care, there continues to be a large group of children that needs to be the focus of applied research in order to determine and improve their well-being. Delving deeper into the reasons that residential care is so prevalent, aside from the entry of young migrants who come alone, it should be noted that there are other factors associated with its ongoing implementation. On the one hand, socio-political efforts have been tame and, according to Delgado et al. (2020), have lacked the conviction to reduce residential care and make foster care more widespread. Indeed, it is only recently that a legislative amendment has recommended that children under 6 years of age do not enter residential care (Act 26/2015). According to data from the Spanish Childhood Observatory (2020), this goal had still not been fully achieved at the end of 2019: 5\% of children in residential care were under 6 years of age and 9\% were aged between 7 and 10. These children were mainly of Spanish origin and no differences were found according to gender. One reason identified in the study by López and Valle (2015) to explain why the population under 12 was in residential care was a lack of foster families. This reveals how the foster care programmes that began in Spain in the 1990s have generally been very underdeveloped (Del Valle et al. 2009). An important difference is noted from other countries in this regard, mainly English-speaking ones, where residential care is conceived as therapeutic and reserved for adolescents with severe behavioural problems (Whittaker et al. 2016). In Spain, many of the children in residential care are there due to a lack of foster care places. Care must therefore be taken when making cross-country comparisons (Martín et al. 2018). There are also historical reasons for this, with fewer advances in democracy and cultural awareness, with a certain trust in residential care and children being cared for by people outside the family being perceived with distrust (see Del Valle and Casas 2002). This also explains the high levels of kinship foster care within the system (Del Valle et al. 2009).

\subsection{The Subjective Well-Being of Children in Residential Care}

Research on the subjective well-being of children in the care system is still in its infancy both nationally and internationally. Studying children's subjective well-being allows us to understand their points of view on different aspects of their lives, the evaluations they make 
and the perceptions they have about their lives, and in particular about the residential home where they are accommodated, their family of origin, school, use of time and their perceptions regarding the future, among other aspects. In Spain, Llosada-Gistau et al. $(2015,2017)$ have carried out studies focusing on this population and have reported higher well-being scores among those living in kinship and non-kinship foster families, which are fairly similar to those of the general child population, while they observed significantly lower scores among the population in residential care. Specifically, the mean score on the PWI-SC scale stands at 80.70 out of 100 for children in care; however, those in residential care have a lower SWB (75.87) than those in kinship (87.91) and non-kinship foster care (86.78), with significant differences $(p<0.01)$. Another study compared the subjective well-being of children in care in Spain and Portugal (Carvalho et al. 2020). In Portugal, the mean score on the PWI-SC scale stands at 78.4 (SD 1.77) for those in residential care and 87.6 (SD 1.03) for those in family foster care. Similar studies in Brazil (Schütz et al. 2015) have also focused on residential care population. On the PWI-SC, those in residential centres are 77.8 (SD 1.95) compared to those living with their families at 87.9 (0.93). González-García et al. (2021) recently studied this phenomenon in the population of residential homes accommodating children with behavioural problems and observed that girls scored significantly lower in life satisfaction. Satisfaction with life as a whole (OLS) in boys obtained a mean of 73.4 (SD 2.76) and among girls a mean of 56.6 (SD 3.16). These differences by gender coincide with those previously noted by Llosada-Gistau et al. $(2017,2019)$ and with Ortúzar et al. (2019) in Chile and Peru, where boys present higher levels of well-being than girls in all measurements. For instance, in the OLS scale, differences are significant by sex $[\mathrm{t}(364)=438,706$, $p<0.001)$. It is important to note that in all the above countries, residential care is the most common measure, with very few children in foster care. All of these recent studies (Catalonia, Brazil, Portugal, Chile and Peru) used an adaptation of the Children's Worlds questionnaire (for more details, see Llosada-Gistau et al. 2015). This has allowed for a comparison of data, as well as a comparison with those of the general population. It has revealed a situation of disadvantage among children in residential care, while at the same time constituting a robust line of cross-country research.

What is the value of studying SWB in this population? First, as children, like the rest of the population at the same ages, it underlines the fact that we should consider childhood as a stage of life with its own sociological characteristics (Ben-Arieh 2008) and assume that subjective social indicators may be as useful as objective indicators in decision making and in promoting social policies. It also emphasizes that children should be regarded not merely as passive subjects but as active social stakeholders; we should listen to their opinions and evaluations (children's rights were considered in the 1989 UNC). Moreover, SWB enables us to study the positive aspects of childhood from the perspective of childhood and not just from the more common approach of considering what the children may become as adults (Casas 2011).

Secondly, and specifically with this population, the study of SWB allows us to identify which factors or conditions of the protection system help to increase children's well-being in care, such as the existence of stability, the prioritization of school or their levels of participation in issues that affect them (for more details, see Garcia-Molsosa et al. 2019), and in which type of placement they are most likely to be found. At the same time, it still needs to be confirmed whether the results remain stable over the years (and across countries) as well as whether the social context may influence the results. This is explored further in the next section.

\subsection{Measuring Subjective Well-Being over Time}

To date, few studies have re-administered the subjective well-being questionnaire after a few years, meaning there is a lack of information on trends in these children's subjective well-being over time, and on the reliability of the items studied over time. In a study on foster care by Montserrat and Casas (2006), the questionnaire was re-administered after one year and it was observed that the mean responses obtained for most of the questions 
did not show any statistically significant differences. There was a positive and significant correlation between most responses from one year to the next, and this consistency in responses suggested that the perceptions and evaluations of foster children were stable, and that the items used in the questionnaire over time were reliable. However, we have not been able to identify any further research in this regard. Having more data would thus allow us to better understand the points of view of children in residential care, have more elements to improve the service and finally, promote greater well-being among these children via their direct involvement and participation.

Thus, in order to address this shortcoming in the literature, a study was conducted with the general aim of comparing the subjective well-being of adolescents aged 11 to 14 in residential care in Catalonia (northeast Spain) in 2014 with that reported in 2020. The main research questions are as follows: (i) Is there continuity in the levels of subjective wellbeing - overall and by domains - between boys and girls in residential care in Catalonia after six years? (ii) Are there gender differences as in 2014? (iii) Are there explanations for a possible influence of the COVID-19 pandemic on the results?

In addition, based on the findings, and as a result of the context of the pandemic in which the questionnaires were administered, an attempt has been made to provide possible interpretations of the influence of lockdown measures during COVID-19 on the responses reported in 2020.

\section{Materials and Methods}

The study design is based on the collection of quantitative data by the authors of this article, with the use of the same instrument for the two points of collection and aimed at the same type of population.

\subsection{Participants}

The target population comprised adolescents living in residential care in Catalonia while they could not live with their family of origin. In most cases, this was due to situations of neglect or abuse (56\% of the care system population, according to 2020 data from the Department of Labour, Social Affairs and Families; this figure was $50 \%$ in 2014). The age range- between 11 and 14-was selected in 2014 in order to be able to use the same questionnaire as the one used with the general population in Catalonia by the International Children's Worlds Survey (https: / / isciweb.org/the-questionnaire, accessed on 1 November 2021), which was aimed at the population aged 12-13. In the case of the in-care population, this was deemed the most suitable age range for participants to answer the questionnaire autonomously, and it was maintained for the 2020 collection.

In 2014, the questionnaire was sent to the total population within this age range living in residential care in Catalonia $(\mathrm{N}=526)$, and 376 adolescents responded $(71.5 \%$ response rate). In 2020, it was also sent to the total population aged 11 to $14(\mathrm{~N}=638)$ and 265 questionnaires were returned, representing a response rate of $41.5 \%$.

As Table 1 shows, 572 responses were analysed. Questionnaires with more than three items missing from the well-being index were not included. Of the respondents analysed, girls comprised $46.4 \%$ in 2014 and $44.2 \%$ in 2020 (the difference is not significant), 16\% and $21 \%$ were born abroad, respectively, and the average age for each data collection was 13.1 and 12.7, respectively. This distribution in terms of age, gender and origin in both 2014 and 2020 is very similar to that of the whole population of children in residential care in Catalonia in this age group (DGAIA 2021; Llosada-Gistau et al. 2015), which, despite the lower response rate in 2020, means the sample is sufficiently representative. 
Table 1. Distribution of the sample by gender and year of data collection.

\begin{tabular}{ccccccc}
\hline & 2014 Sample & $\mathbf{\%}$ & 2020 Sample & $\mathbf{\%}$ & Total & $\mathbf{\%}$ \\
\hline Boys & 195 & $53.6 \%$ & 116 & $55.8 \%$ & 311 & $54.4 \%$ \\
\hline Girls & 169 & $46.4 \%$ & 92 & $44.2 \%$ & 261 & $45.6 \%$ \\
\hline Total & 364 & $100.0 \%$ & 208 & $100.0 \%$ & 572 & $100.0 \%$ \\
\hline
\end{tabular}

\subsection{Instruments and Procedure}

A self-reported anonymous on-line questionnaire was used for data collection, which included the subjective well-being items already used in a previous adapted and tested version of the International Children's Worlds Survey questionnaire (https:/ /isciweb.org/ the-questionnaire, accessed on 1 November 2021) (see Llosada-Gistau et al. 2015), following the question, 'How satisfied are you with each of the following things in your life?'. The eleven questions on subjective well-being analysed (on an 11-point scale from 0 to 10, from 'Do not agree at all' to 'Totally agree') included a single item scale focusing on Overall Life Satisfaction (OLS) and ten questions on the children's satisfaction with different domains of their lives: health, the things you have, safety, what can happen to you later in life, the use of time, friends, the area where you live, classmates, the freedom you have and how adults listen to you.

A pilot test was conducted in both 2014 and 2020: in 2014, eight boys and eight girls participated from one home, and in 2020, four boys and five girls from another residential home participated. After they had answered the questionnaire, a discussion group was held (face-to-face in 2014 and online in 2020), where the children explained their views on the questionnaire to the researchers.

In both 2014 and 2020, the questionnaire was sent to residential home directors by the child protection authorities in Catalonia, so that they could then pass it on to the children in the target age group and provide guidance to help those with reading comprehension, language or attention problems. The children could choose between Catalan and Spanish versions.

\subsection{Data Analysis}

Two types of analysis were performed to analyse the data: on the one hand, a descriptive analysis of the samples from both waves, and on the other, a bivariate analysis to compare the means for the items on satisfaction with life included in the two questionnaires, which were comparable because their wording was identical. A dual comparison was carried out using the selected items on satisfaction: first, the means according to the gender of the adolescents (between boys and girls) for each of the years analysed, and then the means for boys and girls separately between the two years (boys in 2014 compared to boys in 2020, and the same for girls). These comparisons were conducted using the Student's T test for two independent samples. The data have been compared by gender to check if the differences found in 2014 persist six years later.

\subsection{Ethical Considerations}

This research was approved and authorized by the Spanish child protection authorities for both the 2014 and 2020 collections. The children who answered the questionnaires participated anonymously, voluntarily and without receiving any incentive. The research team signed a contract with the authorities containing all aspects of data processing and confidentiality, and no personal data were accessed, including the e-mail addresses of the residential homes, since the authorities were responsible for the administration and sending of the questionnaires. The research has preserved the confidentiality of the cases and complied with Act 3/2018 on the protection of personal data and the guaranteeing of digital rights. 


\section{Results}

Table 2 shows the proportion of boys and girls who reported scores below or equal to 7 (which we have considered low SWB) and the proportion who reported scores above 7 (which we have considered normal or high SWB) for the OLS scale and for the other satisfaction items included in the study.

Table 2. Proportion (\%) of participants who reported low and high scores for different subjective well-being domains and for overall life satisfaction (OLS) by gender and year of data collection.

\begin{tabular}{|c|c|c|c|c|c|c|c|c|}
\hline & \multicolumn{4}{|c|}{2014} & \multicolumn{4}{|c|}{2020} \\
\hline & \multicolumn{2}{|c|}{ Low SWB $(\leq 7)$} & \multicolumn{2}{|c|}{ High SWB (>7) } & \multicolumn{2}{|c|}{ Low SWB $(\leq 7)$} & \multicolumn{2}{|c|}{ High SWB (>7) } \\
\hline & Boys & Girls & Boys & Girls & Boys & Girls & Boys & Girls \\
\hline OLS & $38.5 \%$ & $60.4 \%$ & $61.5 \%$ & $39.6 \%$ & $42.2 \%$ & $43.5 \%$ & $57.8 \%$ & $56.5 \%$ \\
\hline Satisfaction health & $21.0 \%$ & $29.6 \%$ & $79.0 \%$ & $70.4 \%$ & $20.4 \%$ & $24.7 \%$ & $79.6 \%$ & $75.3 \%$ \\
\hline Satisfaction with the things you have & $50.3 \%$ & $48.5 \%$ & $49.7 \%$ & $51.5 \%$ & $45.0 \%$ & $29.2 \%$ & $55.0 \%$ & $70.8 \%$ \\
\hline Satisfaction with safety & $35.4 \%$ & $58.6 \%$ & $64.6 \%$ & $41.4 \%$ & $47.6 \%$ & $45.9 \%$ & $52.4 \%$ & $54.1 \%$ \\
\hline $\begin{array}{l}\text { Satisfaction with what may happen to } \\
\text { you later in life }\end{array}$ & $37.4 \%$ & $53.7 \%$ & $62.6 \%$ & $46.3 \%$ & $47.6 \%$ & $51.2 \%$ & $52.4 \%$ & $48.8 \%$ \\
\hline Satisfaction with your use of time & $47.2 \%$ & $52.7 \%$ & $52.8 \%$ & $47.3 \%$ & $43.6 \%$ & $42.7 \%$ & $56.4 \%$ & $57.3 \%$ \\
\hline Satisfaction with friends & $31.4 \%$ & $21.3 \%$ & $68.6 \%$ & $78.7 \%$ & $28.4 \%$ & $27.3 \%$ & $71.6 \%$ & $72.7 \%$ \\
\hline Satisfaction with the area where you live & $29.5 \%$ & $42.2 \%$ & $70.5 \%$ & $57.8 \%$ & $46.8 \%$ & $51.7 \%$ & $53.2 \%$ & $48.3 \%$ \\
\hline Satisfaction with classmates & $33.9 \%$ & $46.8 \%$ & $66.1 \%$ & $53.2 \%$ & $48.7 \%$ & $42.1 \%$ & $51.3 \%$ & $57.9 \%$ \\
\hline Satisfaction with the freedom you have & $56.2 \%$ & $63.7 \%$ & $43.8 \%$ & $36.3 \%$ & $58.7 \%$ & $57.1 \%$ & $41.3 \%$ & $42.9 \%$ \\
\hline Satisfaction with how adults listen to you & $36.4 \%$ & $46.8 \%$ & $63.6 \%$ & $53.2 \%$ & $35.6 \%$ & $31.8 \%$ & $64.4 \%$ & $68.2 \%$ \\
\hline
\end{tabular}

Splitting two groups below and above 7 points out of 10 is justified because, in general, the subjective well-being of most people is stable and predictable between 70 and 90 points out of 100 points (Cummins 2010). Scores below 70 points could indicate that personal homeostasis is not enough to cope with difficult or stressful life situations that affect people.

The data in the table show us that the proportion of girls with low SWB decreases in the 2020 sample compared to the 2014 one in most of the items analysed. Outstanding differences are observed, for example, in the different proportions of the OLS scale (from $60.4 \%$ to $43.5 \%$ ) or of Satisfaction with the things you have (from $48.5 \%$ to $29.2 \%$ ). The only two items in which the proportion of low SWB is higher in 2020 compared to 2014 are Satisfaction with the area where you live (from $42.2 \%$ to $51.7 \%$ ) and Satisfaction with friends (from $21,3 \%$ to $27.3 \%$ ). Among boys, the proportions between both years are more similar than among girls. However, a higher proportion of low SWB is observed in 2020 compared to 2014, especially with regard to the Satisfaction with safety (from 35.4\% to 47.6\%), Satisfaction with the area where you live (from $29.5 \%$ to $46.8 \%$ ) and Satisfaction with classmates (from $33.9 \%$ to $48.7 \%$ ).

No significant differences in means were observed between the 2014 and 2020 waves for most of the life satisfaction items selected for this study. Differences were only observed between the following items: satisfaction with friends $(p<0.05)$, satisfaction with classmates $(p<0.01)$ and satisfaction with the area where you live $(p<0.001)$. In all three items, the overall means for 2020 were lower than those for 2014.

Second, if we compare the satisfaction means between boys and girls for the years 2014 and 2020, we observe that boys displayed greater satisfaction than girls for most of the items analysed in 2014, the majority of these differences being statistically significant $(p<0.05)$. However, these differences did not persist six years later (bearing in mind that the second sample was obtained just after the enforced lockdown due to the COVID-19 
pandemic). Thus, in the 2020 sample, it is observed that none of the selected items achieved statistical significance in the comparison by gender.

Figure 2 shows differences by gender in the overall life satisfaction index measured using a single item (Overall Life Satisfaction-OLS). Significant gender differences were observed in the 2014 wave (where girls scored lower than boys), while these decreased in the 2020 wave.

\section{4}

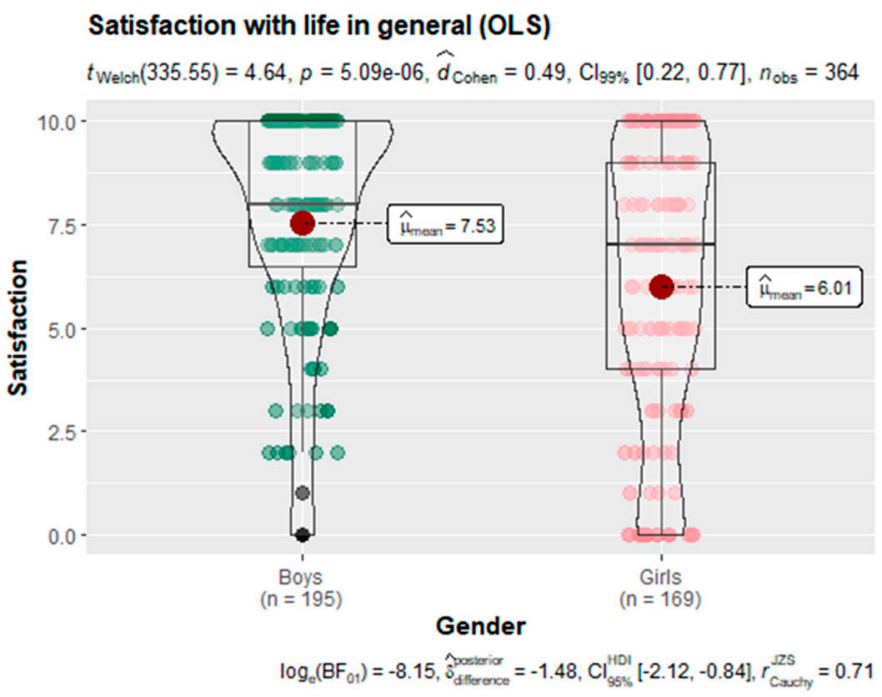

2020

Satisfaction with life in general (OLS)

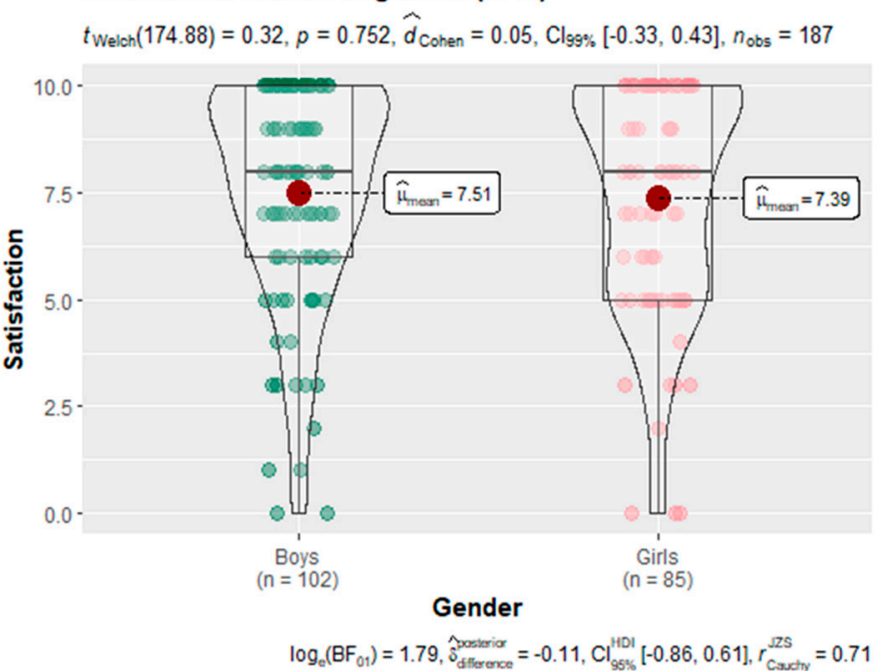

Figure 2. Comparison of means for Overall Life Satisfaction (OLS) by gender and year of data collection.

It is particularly worth highlighting the change displayed by girls in the index on overall satisfaction with life measured using a single item (Overall Life Satisfaction-OLS): while in 2014 they barely exceeded a mean satisfaction score of 6 points out of 10, thus displaying significantly lower satisfaction than boys, in 2020 they reported a mean score of 7.39, which does not significantly differ from the 7.5 points displayed by boys for both years (see Table 3 and Figure 3).

Table 3. Comparison of means of the comparable satisfaction items between both samples by gender and year of data collection.

\begin{tabular}{|c|c|c|c|c|c|c|c|c|}
\hline & \multicolumn{3}{|c|}{2014} & \multicolumn{3}{|c|}{2020} & \multicolumn{2}{|c|}{$\begin{array}{l}p \text {-Values Comparison } \\
\text { for the Two Years }\end{array}$} \\
\hline & Boys & Girls & $p$-Value & Boys & Girls & $p$-Value & Boys & Girls \\
\hline OLS & 7.53 & 6.01 & $p<0.001$ & 7.51 & 7.39 & $p=0.752$ & $p=0.955$ & $p<0.001$ \\
\hline Satisfaction health & 8.82 & 8.16 & $p=0.005$ & 8.46 & 8.21 & $p=0.453$ & $p=0.150$ & $p=0.869$ \\
\hline Satisfaction with the things you have & 7.25 & 7.08 & $p=0.537$ & 7.80 & 8.30 & $p=0.073$ & $p=0.042$ & $p<0.001$ \\
\hline Satisfaction with safety & 8.06 & 6.70 & $p<0.001$ & 7.49 & 7.13 & $p=0.375$ & $p=0.049$ & $p<0.273$ \\
\hline $\begin{array}{l}\text { Satisfaction with what may happen to } \\
\text { you later in life }\end{array}$ & 7.78 & 6.75 & $p<0.001$ & 7.32 & 7.05 & $p=0.465$ & $p=0.135$ & $p=0.412$ \\
\hline Satisfaction with your use of time & 7.33 & 6.99 & $p=0.204$ & 7.72 & 7.72 & $p=0.998$ & $p=0.159$ & $p=0.009$ \\
\hline Satisfaction with friends & 8.20 & 8.53 & $p=0.131$ & 8.34 & 7.97 & $p=0.314$ & $p=0.555$ & $p=0.112$ \\
\hline Satisfaction with the area where you live & 8.06 & 7.44 & $p=0.023$ & 7.10 & 6.69 & $p=0.357$ & $p=0.005$ & $p=0.057$ \\
\hline Satisfaction with classmates & 8.00 & 7.13 & $p=0.002$ & 7.07 & 7.28 & $p=0.626$ & $p=0.006$ & $p=0.695$ \\
\hline Satisfaction with the freedom you have & 6.30 & 5.70 & $p=0.085$ & 6.46 & 6.62 & $p=0.721$ & $p=0.678$ & $p=0.028$ \\
\hline Satisfaction with how adults listen to you & 7.82 & 7.20 & $p=0.023$ & 7.63 & 7.84 & $p=0.574$ & $p=0.532$ & $p=0.060$ \\
\hline
\end{tabular}




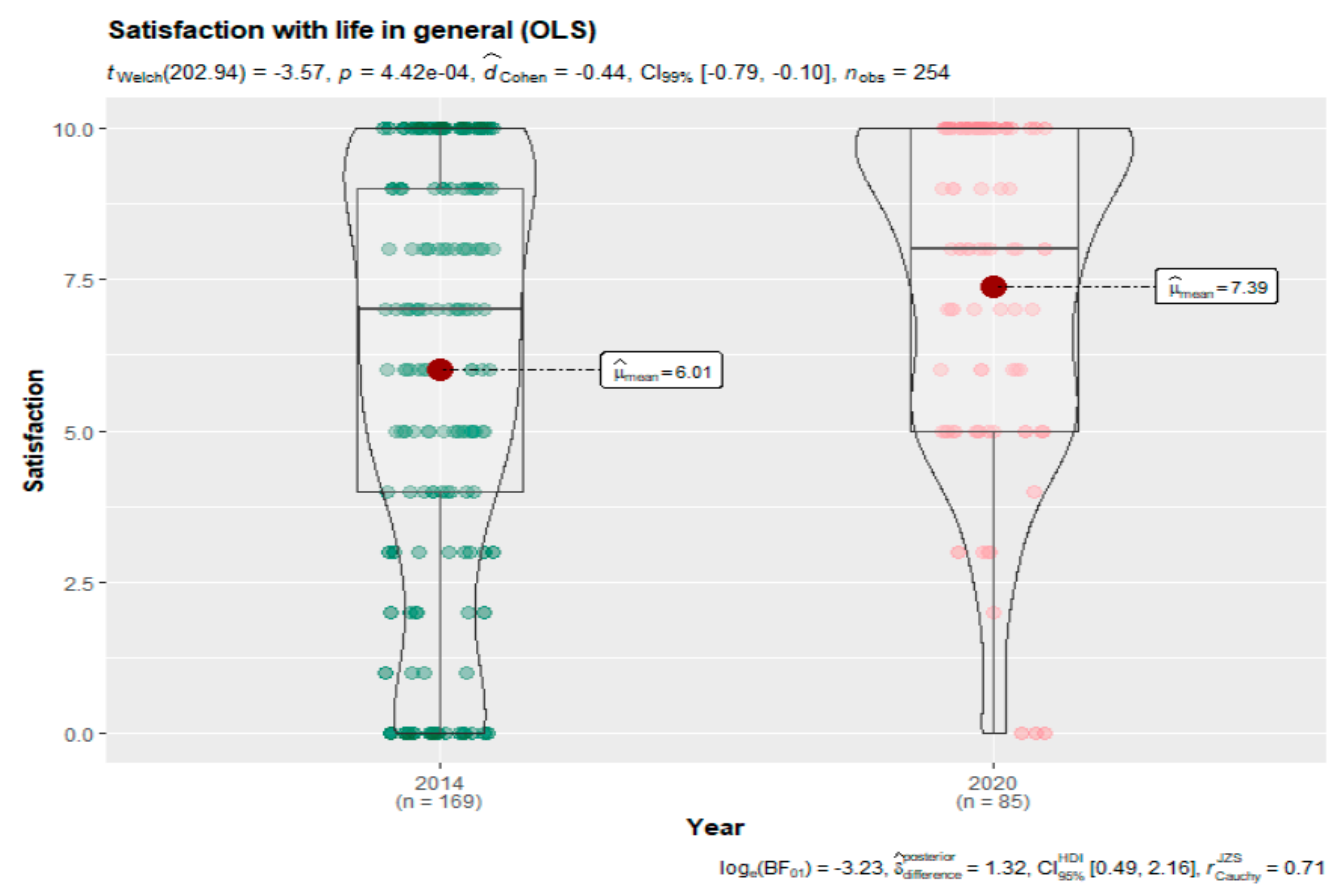

Figure 3. Comparison of means for satisfaction with life in general (OLS) among girls by year of data collection.

If we analyse only the satisfaction means for both years among girls, the means shown for 2020 exceed those of 2014 in most of the selected satisfaction items. The most noteworthy changes are the increase in OLS (+1.38 points), satisfaction with the things you have (+1.23 points) and satisfaction with the freedom you have (+0.92 points). The two satisfaction items that decreased in 2020 compared to 2014 were satisfaction with the place where you live $(-0.75)$ and satisfaction with friends $(-0.56)$, although neither reached statistical significance $(p>0.05)$.

Among boys, most of the selected satisfaction items remained stable between the two years. However, a decrease was observed in satisfaction with the area where you live $(-0.96$ points), satisfaction with classmates $(-0.93)$ and satisfaction with safety $(-0.57)$. Figure 4 shows this decrease in satisfaction with classmates among boys between 2014 and 2020. All three items showed statistically significant differences between the two years $(p<0.05)$. On the other hand, the only item where boys displayed greater satisfaction in 2020 compared to 2014 was in satisfaction with the things you have $(+0.55)$, as was also the case among girls of the same age. 


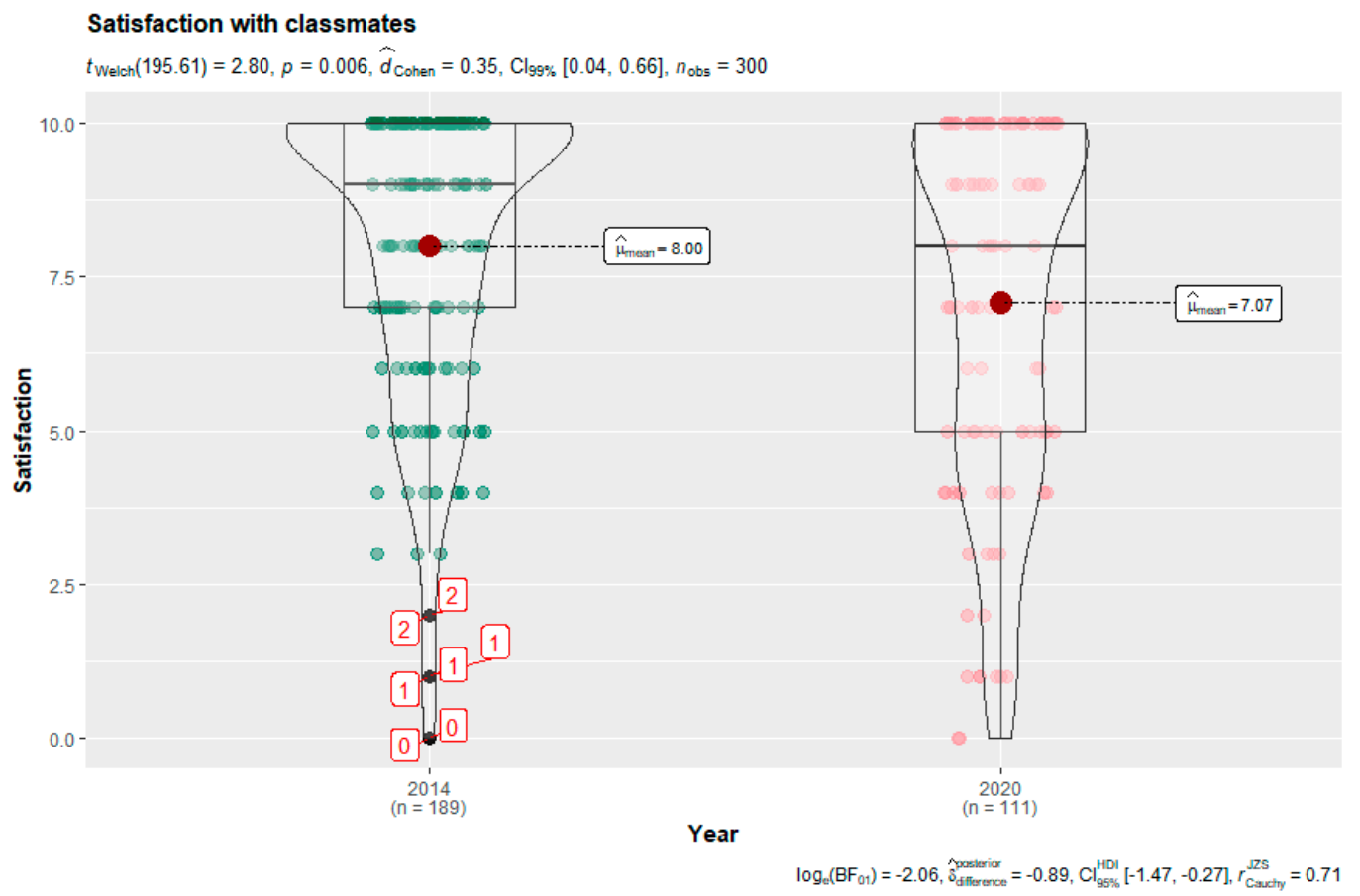

Figure 4. Comparison of means for satisfaction with classmates among boys by year of data collection.

\section{Discussion}

The results of the present study show a continuity in the levels of subjective well-being among boys and girls in residential care in Catalonia between 2014 and 2020, endorsing the reliability of the responses given by boys and girls in previous studies (Montserrat and Casas 2006). Thus, on the one hand, the usefulness of the questionnaire adapted by Llosada-Gistau et al. (2015) in evaluating the subjective well-being of boys and girls in the care system is confirmed. On the other hand, the relevance and need for studies based on the subjective well-being of children and adolescents is reaffirmed, including collecting their own perceptions as a reference for organizing and defining, in this case, resources for residential care.

According to these results, the subjective well-being of boys and girls aged between 11 and 14 in residential care in Catalonia has remained stable over time, as happened with children in foster care (Montserrat and Casas 2006). Consistently, their scores are in the lower range compared to other children inside and outside the care system (Llosada-Gistau et al. 2015, 2017). These results reinforce the need to review such placements and promote family fostering, when possible, since research has also identified worse outcomes for children in residential care in other areas such as education, sociability or health (e.g., Garcia-Molsosa et al. 2020). On the one hand, this consistency was to be expected, since there have been no structural changes in terms of residential care in the Spanish care system over the last five years, such as a reduction in the number of places per home, staff stability or an improvement in the children's educational situation or social capital and participation (Carvalho et al. 2020; Garcia-Molsosa et al. 2019). Neither has the profile of boys and girls accommodated in homes in Catalonia in this age group changed significantly, meaning similar responses can therefore be expected (DGAIA 2021). The number of foreign adolescents has increased, but this increase has mainly been seen in adolescents who are 15 years old and above. Finally, this constancy in the results fits with the homeostasis principle of "subjective well-being", which justifies its stability over time, in contrast with individuals' emotional states (Cummins 2010).

However, three items displayed differences between 2014 and 2020: satisfaction with friends, with classmates and with the area where you live, with the overall means for 2020 being lower than in 2014. Presumably, the effects of the pandemic and the consequent lockdown could explain these differences in all three items with respect to 2014, in the sense that 
it has probably been difficult to maintain relationships with friends and/or classmates due to limitations in social interactions among the entire child population, but especially those in residential care, due to the logistical difficulties and resource requirements (human, material) that this entails (Montserrat et al. 2021). As for the low level of satisfaction with the place where you live (referring to the neighbourhood), this may also be due to the conditions of confinement experienced during lockdown, in which boys and girls did not have the option to move freely around their local area. However, future studies should be undertaken to explore these three aspects in greater depth, since the results do not allow us to confirm or refute these hypotheses. As a counterargument to them, studies such as the one conducted by Vallejo-Slocker et al. (2020) have questioned the potential impact that COVID-19 lockdowns may have had among this population in terms of their subjective well-being. However, others claim that there may have been changes in their family situation (more "hurried" returns home) or the emergence of feelings of anguish or concern regarding the health and possible loss of loved ones, in line with Haffejee and Levine (2020) and Wilke et al. (2020). These elements are not included in the questionnaire administered in this study and should be taken into account in subsequent analyses. It should also be borne in mind that the effects of the pandemic may emerge later, with a worsening of mental health among the child and adolescent population, especially the more vulnerable (Romero et al. 2020), and of their educational situation (Bonal and González 2020), elements that are not included in this study and that will need to be explored further.

Another result that may have been influenced by the lockdowns has been the improvement these adolescents express in terms of satisfaction with the things they have, which may be related to improvements that the residential homes have been obliged to quickly implement in terms of material conditions, especially in relation to access to electronic devices, computers, mobile phones and internet connections. This was the only means the homes had to allow the children who lived there to attend school classes online.

As for differences in SWB due to gender, the results reveal that these are not as obvious or as clear as they were in 2014. This result was unexpected and may also contradict the scientific literature in the field of children's care (Dinisman et al. 2012; Llosada-Gistau et al. 2019; Martín 2015; Selwyn et al. 2016), where girls have reported lower subjective well-being scores than boys. As an explanation for this, we could hypothesize a possible "positive effect" of COVID-19 lockdown measures on girls in residential care, perhaps due to their being less exposed to the social life in which they find themselves in a situation of greater vulnerability due to their family situation and gender factors. Authors such as Kaye-Tzadok et al. (2017) have pointed out that the area where girls are less satisfied compared to boys is that of interpersonal relationships, and in this study, lockdowns may have allowed them to be less exposed to conflict, an issue that should be explored more in the future to determine whether this hypothesis is supported by the evidence.

All that being said, according to a recent study (Montserrat et al. 2021), this positive effect may have been due to an improvement in relationships with social educators in the residential homes and the fact of finding in them a trusted person during lockdown, together with an improvement in academic results, also as a result of lockdown. These hypotheses gain weight if we take into account the results of previous studies, wherein precisely these aspects were found to be least satisfactory among children and adolescents in residential care (Ortúzar et al. 2019; Garcia-Molsosa et al. 2019). Another possible explanation is that school professionals have begun to incorporate a gender perspective into their interventions, given the social pressure to do so. These results will need to be followed very closely in order to see how this aspect evolves in the future, thus representing a clear impetus for future research.

The most important limitation of this research was probably having administered the questionnaire during full lockdown, which has led to our venturing hypotheses that will have to be tested in the future. At the same time, however, this did present an opportunity to verify that despite changing environmental conditions, the measurement of subjective well-being remains quite stable over time and differences are concentrated mainly in 
the field of interpersonal relationships, which constitute the relations most affected by lockdown. It will be necessary to complement this study with a more qualitative approach with regard to the opinions of children and adolescents, whose experiences and concerns will help us explain their subjective well-being as well as formulate hypotheses about the changes that have taken place over time. There is therefore an evident need for further longitudinal research in this regard.

Despite the limitations of this study, some implications for policy and practice can be suggested based on its results. On the one hand, family foster care should be encouraged as the best way to endorse factors that increase children's well-being, such as stability, the prioritization of school or higher levels of participation among children in care. On the other hand, residential care should be improved regarding: (1) the promotion of relationships with peers outside the residential centre, including in times of crisis. In order to do so, logistical and resource limitations must be overcome. (2) Professionals in residential centres should be stabilised and cared for, considering their importance in children's lives, especially in times of crisis. (3) Caregivers must adopt a gender perspective to better fit girls' particular socio-emotional needs.

Author Contributions: Conceptualization, C.M., J.L.-G., M.G.-M. and F.C.; methodology, J.L.-G.; software, J.L.-G. and F.C.; formal analysis, J.L.-G. and F.C.; investigation, M.G.-M.; resources, M.G.-M.; data curation, J.L.-G. and M.G.-M.; writing—original draft preparation, C.M. and M.G.-M.; writing—review and editing, C.M.; supervision, F.C.; project administration, C.M.; funding acquisition, C.M. All authors have read and agreed to the published version of the manuscript.

Funding: This research received external funding from DGAIA [Catalan Directorate General of Child and Adolescent Care], Catalan government.

Institutional Review Board Statement: The study was conducted in accordance with the Declaration of Helsinki, and approved by the Institutional Review Board of Generalitat de Catalunya (protocol code BE-2020-2159, date 12 March 2020).

Informed Consent Statement: Informed consent was obtained from all subjects involved in the study.

Data Availability Statement: The data that support the findings of this study are available on Dataverse (https:/ / doi.org/10.34810/data118 accessed on 1 November 2021).

Acknowledgments: Thanks to the young people who have participated in the study.

Conflicts of Interest: The authors declare no conflict of interest. The funders had no role in the design of the study, in the collection, analyses or interpretation of data, in the writing of the manuscript or in the decision to publish the results.

\section{References}

Ben-Arieh, Asher. 2008. The child indicators movement: Past, present and future. Child Indicators Research 1: 3-16. [CrossRef]

Bonal, Xavier, and Sheila González. 2020. The impact of lockdown on the learning gap: Family and school divisions in times of crisis. International Review of Education 66: 635-55. [CrossRef]

Carvalho, Joao, Paulo Delgado, Carme Montserrat, Joan Llosada-Gistau, and Ferran Casas. 2020. Subjective Well-Being of Children in Care: Comparison between Portugal and Catalonia. Child and Adolescent Social Work Journal 38: 81-90. [CrossRef]

Casas, Ferran. 2011. Subjective Social Indicators and Child and Adolescent Well-being. Child Indicators Research 4: 555-75. [CrossRef]

Cummins, Robert A. 2010. Subjective Wellbeing, homeostatically protected mood and depression: A synthesis. Journal of Happiness Studies 11: 1-17. [CrossRef]

Del Valle, Jorge Fernández, and Ferran Casas. 2002. Child residential care in the Spanish social protection system. International Journal of Child and Family Welfare 5: 112-28.

Del Valle, Jorge Fernández, Mónica López, Carme Montserrat, and Amaia Bravo. 2009. Twenty years of foster care in Spain. Profiles, patterns and outcomes. Children and Youth Services Review 31: 847-53. [CrossRef]

Delgado, Paulo, Joao Carvalho, Carme Montserrat, and Joan Llosada-Gistau. 2020. The Subjective Well-Being of Portuguese Children in Foster Care, Residential Care and Children Living with their Families: Challenges and Implications for a Child Care System Still Focused on Institutionalization. Child Indicators Research 13: 67-84. [CrossRef]

DGAIA [Catalan Directorate General of Child and Adolescent Care]. 2021. Official Statistics on Child Protection. Available online: https: / treballiaferssocials.gencat.cat/ (accessed on 1 November 2021). 
Dinisman, Tamar, Carme Montserrat, and Ferran Casas. 2012. The subjective well-being of Spanish adolescents: Variations according to different living arrangements. Children and Youth Services Review 34: 2374-80. [CrossRef]

Garcia-Molsosa, Marta, Jordi Collet-Sabé, Joan Carles Martori, and Carme Montserrat. 2019. School satisfaction among youth in residential care: A multi-source analysis. Children and Youth Services Review 105: 1-8. [CrossRef]

Garcia-Molsosa, Marta, Jordi Collet-Sabé, and Carme Montserrat. 2020. What are the factors influencing the school functioning of children in residential care: A systematic review. Children and Youth Services Review 120: 105740. [CrossRef]

González-García, Carla, Alba Águila-Otero, Carme Montserrat, Susana Lázaro-Visa, Eduardo Martín, Jorge Fernández del Valle, and Amaia Bravo. 2021. Subjective well-being of young people in therapeutic residential care from a gender perspective. Child Indicators Research 15: 249-62. [CrossRef]

Haffejee, Sadiyya, and Diane Thembekile Levine. 2020. 'When will I be free': Lessons from COVID-19 for Child Protection in South Africa. Child Abuse \& Neglect 110: 104715. [CrossRef]

Kaye-Tzadok, Avital, Sun Suk Kim, and Gill Main. 2017. Children's subjective well-being in relation to gender. What can we learn from dissatisfied children? Children and Youth Services Review 80: 96-104. [CrossRef]

Llosada-Gistau, Joan, Carme Montserrat, and Ferran Casas. 2015. The subjective well-being of adolescents in residential care compared to that of the general population. Children and Youth Services Review 52: 150-57. [CrossRef]

Llosada-Gistau, Joan, Ferran Casas, and Carme Montserrat. 2017. What matters in for the subjective well-being of children in care? Child Indicators Research 10: 735-60. [CrossRef]

Llosada-Gistau, Joan, Ferran Casas, and Carme Montserrat. 2019. The subjective well-being of children in kinship care. Psicothema 31: 149-55. [CrossRef]

López, Mónica, and Jorge Fernández del Valle. 2015. The waiting children: Pathways (and future) of children in long-term residential care. British Journal of Social Work 45: 457-73. [CrossRef]

Martín, Eduardo. 2015. Niños, niñas y adolescentes en acogimiento residencial. Un análisis en función del género [Children and adolescents in residential care. A gender analysis]. Qurriculum 28: 91-105.

Martín, Eduardo, Carla González-García, Jorge Fernández del Valle, and Amaia Bravo. 2018. Therapeutic residential care in Spain. Population treated and therapeutic coverage. Child \& Family Social Work 23: 1-7. [CrossRef]

Montserrat, Carme, and Ferran Casas. 2006. Kinship foster care from the perspective of quality of life: Research on the satisfaction of the stakeholders. Applied Research in Quality of Life 1: 227-37. [CrossRef]

Montserrat, Carme, Marta Garcia-Molsosa, Joan Llosada-Gistau, and Rosa Sitjes-Figueras. 2021. The views of children in residential care on the COVID-19 lockdown: Implications for and their well-being and psychosocial intervention. Child Abuse E Neglect 120: 105182. [CrossRef]

Ortúzar, Harry, Rafael Miranda, Xavier Oriol, and Carme Montserrat. 2019. Self-control and subjective-wellbeing of adolescents in residential care: The moderator role of experienced happiness and daily-life activities with caregivers. Children and Youth Services Review 98: 125-31. [CrossRef]

Romero, Estrella, Laura López-Romero, Beatriz Domínguez-Álvarez, Paula Villar, and Jose Antonio Gómez-Fraguela. 2020. Testing the effects of COVID-19 confinement in Spanish children: The role of parents' distress, emotional problems and specific parenting. International Journal of Environmental Research and Public Health 17: 6975. [CrossRef]

Schütz, Fabiane, Jorge Sarriera, Livia Bedin, and Carme Montserrat. 2015. Subjective well-being of children in residential care: Comparison between children in institutional care and children living with their families. Psicoperspectivas 14: 19-30. [CrossRef]

Selwyn, Julie, Marsha Wood, and Tabitha Newman 2016. Looked after children and young people in England: Developing measures of subjective well-being. Child Indicators Research 10: 363-80. [CrossRef]

Spanish Childhood Observatory [Observatorio de la Infancia]. 2020. Boletín de datos estadísticos de medidas de protección a la infancia. Boletín 22 [Spanish Child Protection Figures. Bulletin 22]. Ministerio de Sanidad, Consumo y Bienestar Social. Available online: https:/ / observatoriodelainfancia.vpsocial.gob.es/productos/pdf/BOLETIN_22_final.pdf (accessed on 1 November 2021).

Vallejo-Slocker, Laura, Javier Fresneda, and Miguel Vallejo. 2020. Psychological Wellbeing of Vulnerable Children during the COVID-19 Pandemic. Psicothema 32: 501-7. [CrossRef] [PubMed]

Whittaker, James, Lisa Holmes, Jorge Fernández Del Valle, Frank Ainsworth, Tore Andreassen, James Anglin, and Anat Zeira. 2016. Therapeutic residential Care for Children and Youth: A consensus statement of the international work group on therapeutic residential care. Residential Treatment for Children \& Youth 33: 89-106. [CrossRef]

Wilke, Nicole Gilbertson, Amanda Hiles Howard, and Philip Goldman. 2020. Rapid return of children in residential care to family as a result of COVID-19: Scope, challenges, and recommendations. Child Abuse E Neglect 110: 104712. [CrossRef] 